IIUM JOURNAL OF EDUCATIONAL STUDIES, 8:2 (2020) 1-2

Copyright $(1)$ IIUM Press

ISSN: 2289-8085

\title{
EDITORIAL
}

\section{An Alternative and Preferred Future of Education}

The push toward online learning is shaped by several major events and factors. The major catalyst, of course, is the COVID19 pandemic. Whereas, the blended learning policy to prepare our young generation to be future-ready sets the stage for the change that seems inevitable. The current initiatives by the government and the people's call for better facilities to support online learning in ensuring that everyone has access to online platforms is yet another strong push factor. But the greater thrust of all is the belief that online learning is the one and only future for our education landscape that can ensure that learning will take place.

It certainly would not be prudent at all not to recognize the vital role of technology for human development and sustainability. It is equally imprudent to think that technology has all the answers to meet all of our human needs. To ensure learning is not disrupted, we have rushed headlong into online learning without fully ascertaining the extent to which it is necessary, for whom it is necessary, and what other better alternatives could there be for greater educational equity and the well-being of our young and society. We need to look for a more holistic and human-friendly alternative. One that can provide the support that parents, teachers, and students need, and at the same time ensures the social and functional well-being of each and every individual in our society.

For now, we are only addressing the most obvious concern as regards "access" to education. The definition of access which UNESCO has adopted includes "a learning environment that is safe enough to allow learning to take place, and opportunities to learn that are equitably distributed". It is this access to education upon which the education policy of the New Economic Policy (DEB) mirrors. We need to learn from the past but carefully mould it to address our present and future needs. We need to provide access, in the true sense of the word, for those who are not only financially challenged but those who do not have the right environment that would support their learning, regardless of their race and ethnicity.

Thus far, we have ignored the equally important issue of learning support that our children need, especially the young and the challenged. Our approach is too simplistic in addressing the need for access to education, and more importantly, we have overlooked the purpose of education. Education is more than gaining access to information, and it is certainly much more than developing human capital, which is the focus of the industrial revolution. Education is to develop the self to realize what it is to be a responsible and moral human being. Martin Luther King Jr. in his speech in 1948, said "The function of education is to teach one to think intensively and to think critically. But education which stops with efficiency may prove the greatest menace to society. The most dangerous criminal may be the man gifted with reason but no morals. ... We must remember that intelligence is not enough. Intelligence plus character - that is the goal of true education." Education must provide the avenue for our 
young to learn and develop social skills and important values that help build ethics, empathy, and respect. For this, we need to have a more comprehensive approach, not a stopgap reactive measure that will eventually further segregate the haves and have nots, despite the billions of ringgits that we are committed to spending to narrow that very same gap. We need to deeply think about the preferred future for our young. With our present strategy for the future, we are losing the sense of social responsibility and togetherness.

We need to take a step back and consider an alternative and better future than the used future that we are heading towards? A future where the digital divide, even if it persists, does not impede real access to education, regardless of ones' socio-economic status. A future where there is true and equitable access to education, and where dropout rates and risky behaviours are a thing of the past. A future that supports individual learning, as well as collaborative learning and togetherness for societal well-being. To have this preferred future, we should not constraint ourselves into thinking that online learning is the only future that we have. We need to consider alternative futures so that we do not trap ourselves and our forthcoming generation in a future that we do not want. We need a deep transformational change at all levels to realise the preferred future. A transformational change that will enable us to live by our National Philosophy of Education, one of Sejahtera for all humankind.

Prof. Dr. Noor Lide Abu Kassim

Editor-in-Chief of IIUM Journal of Educational Studies (IJES), Kulliyyah of Education,International Islamic University, Malaysia. noorlide@iium.edu.my

December 26, 2020 